\title{
Muito além da diversão: Reflexões sobre a gestão noturna de cidades
}

Far beyond fun: reflections on nigttime city management

\author{
Fernando Burgos Pimentel dos Santos
}

\section{RESUMO}

O Enquanto grande parte das pessoas dorme, uma parcela da população segue acordada, se divertindo ou trabalhando. Importantes cidades do mundo (como Amsterdam, Londres, Nova York e Paris, por exemplo) já perceberam o valor estratégico que a "noite" possui - tanto para a organização da cidade para o dia seguinte, como para a geração de emprego e renda com atividades específicas - mas a administração pública brasileira segue dando pouca atenção para este período do dia. O artigo descreve a disciplina eletiva "Gestão Noturna de Cidades", do curso de Graduação em Administração Pública da FGV-EAESP, cuja inspiração foi a proliferação desses "prefeitos noturnos" internacionais. Por meio de um estudo de caso, analisamos a disciplina que tem carga horária total de 50 horas e ocorre durante uma semana, com aulas começando às $19 \mathrm{~h}$ e terminando às $6 \mathrm{~h}$ do dia seguinte. Os resultados mostram uma mudança de percepção dos(as) estudantes em relação à noite e à importância da gestão pública nesse período.

Palavras-chave: Gestão Noturna; Cidades; Noite; Inovação; Gestão Municipal

\begin{abstract}
While most people sleep, a portion of the population remains awake, having fun or working. Major cities around the world (such as Amsterdam, London, New York, and Paris, among others) already realize the strategic value that "night" has - both for organizing the city for the day after, and for generating jobs and income with specific activities - but the Brazilian public administration continues to pay little attention to this period of the day. The article describes the course "Nighttime City Management" at the FGV-EAESP Undergraduate Program in Public Administration, whose inspiration was the proliferation of these international "night mayors". Through a case study, we analyzed the course that has a total workload of 50 hours and occurs over a week, with classes starting at $7 \mathrm{pm}$ and ending at 6 am the next day. The results show a change in students' perception of the night and the importance of public management during this period.
\end{abstract}

Keywords: Nighttime Management, Cities; Night; Innovation; Municipal Management

\footnotetext{
${ }^{1}$ Doutor em Administração Pública e Governo. Professor do Departamento de Gestão Pública da FGV-EAESP e Coordenador Geral do Centro de Estudos em Administração Pública e Governo (CEAPG/FGV-EAESP). E-mail: fernandoburgos@uol.com.br
} 


\section{Introdução}

À noite, as cidades não deixam de existir. Enquanto grande parte das pessoas dorme, há uma parcela da população que está acordada, se divertindo ou trabalhando. Embora as escolas, universidades, museus, CRAS e outros equipamentos públicos estejam fechados durante a madrugada, há outros serviços públicos que seguem funcionando normalmente, como por exemplo, hospitais, delegacias de polícia, serviços funerários e aeroportos que são absolutamente essenciais à população que deles necessitam. Mas o funcionamento da Administração Pública no período noturno envolve muito mais do que isso, destinandose a organizar a cidade para que o "dia seguinte" funcione normalmente.

O interessante é notar que, apesar do valor estratégico que essas atividades possuem, a administração pública brasileira segue dando pouca atenção para este período do dia. Dessa forma, segue desperdiçando oportunidades interessantes de melhorar a vida e as condições de trabalho dos profissionais que atuam na madrugada, assim como não potencializa atividades e setores econômicos que poderiam gerar trabalho e renda nas cidades. O mesmo ocorre em termos de debate acadêmico, com a total ausência de textos sobre a gestão pública noturna nas revistas acadêmicas brasileiras (dentre os trabalhos estrangeiros, destacamos: Body-Gendrot, 2011; Hadfield, 206; Hollands \& Chatterton, 2003; Nofre et al, 2017; Talbot, 2007, 2011).

As experiências de uma gestão pública específica para o período noturno, em âmbito internacional, começam a se expandir rapidamente em várias cidades. Estima-se que a "noite" da cidade de Nova York gera US $\$ 10$ bilhões anuais, movimentando aproximadamente 100 mil empregos. Em Londres, a estimativa é que o horário noturno movimente US\$ 34 bilhões por ano, incluindo a indústria do entretenimento e os serviços de saúde e assistência social. Buscando aproveitar este potencial e cuidar da gestão da cidade no período noturno, grandes metrópoles europeias como Amsterdam (a pioneira, em 2014), Londres, Paris e Zurique criaram a figura do "prefeito noturno". Nos Estados Unidos, Pittsburgh, Nova York e Washington DC atualmente possuem estruturas administrativas para cuidar da vida noturna. Na América Latina, Cali (Colômbia) e Assunción (Paraguai) já possuem este gestor noturno.

O artigo descreve e analisa uma experiência de disciplina chamada "Gestão Noturna de Cidades", que concebe a "noite" como método e como objetivo, foi ministrada no curso de Graduação em Administração Pública da FGV-EAESP, cuja inspiração foi a proliferação de "prefeitos noturnos" nas grandes cidades europeias e americanas. O objetivo da disciplina é apresentar aos alunos e alunas alguns dos setores econômicos e atividades que funcionam no período noturno em São Paulo e analisar os desafios e potenciais da gestão pública noturna de uma grande metrópole.

Os resultados mostram que a disciplina gerou mudanças de percepções dos(as) estudantes em relação à noite e à importância da gestão pública nesse período. Assim, o título do artigo tem um duplo sentido. De um lado, é mostrar que havia uma expectativa inicial dos(as) estudantes de uma disciplina mais "relaxada" e com grande possibilidade de diversão, em função dela ocorrer durante a madrugada. Afinal, até aquele momento, para a grande maioria deles(as), a noite era o período do lazer e das "baladas". Por outro lado, é para ressaltar que o setor de entretenimento noturno, muito importante para a economia de uma cidade como São Paulo, não é o único que pode se beneficiar com um olhar mais atento por parte das equipes municipais. De maneira mais geral, tanto a disciplinas como o artigo buscam visibilizar - tanto para futuros(as) administradores(as) públicos como para a academia - atividades e serviços públicos cujas importâncias são fundamentais para a gestão das cidades e impactam diretamente a vida das pessoas, incluindo aquelas que costumam dormir durante a noite.

Divide-se o artigo em cinco partes, incluindo esta. Na primeira, há a descrição do método utilizado para a realização da análise. Na segunda, há a descrição do caso, mostrando como a disciplina foi organizada, de forma a permitir que a noite e a madrugada pudessem funcionar como períodos de aprendizagem. A terceira parte traz os trechos escritos pelos próprios alunos, divididos em quatro momentos (antes, durante, agora e depois da disciplina). E nas considerações finais, há um chamamento para que os(as) colegas do campo 
de públicas possam ajudar na reflexão sobre a gestão noturna de cidades, contribuindo para o adensamento da produção acadêmica sobre o tema e também para a melhora dos serviços públicos prestados no período noturno.

\section{Metodologia do artigo}

A metodologia utilizada no artigo foi o estudo de caso (Stake, 1995), buscando descrever a apreensão da experiência pelos estudantes e analisá-la do ponto de vista de uma inovação educacional. Para isso, realizamos análise documental (Bowen, 2009) das "reflexões individuais" feitas pelos(as) estudantes que cursaram a disciplina nos dois semestres de 2018. A reflexão individual é um dos três instrumentos de avaliação, correspondendo a $20 \%$ da nota final, e deve ser entregue por email ao professor no domingo, ou seja, dois dias após o encerramento da disciplina. Os outros dois instrumentos são: nota de participação individual (30\%) e trabalho final em grupo (50\%). A instrução para os(as) alunos(as) é simples: eles devem escrever um texto, com no máximo, 1.500 palavras, explicando quais as suas reflexões sobre a gestão noturna de cidade após a realização da disciplina.

Para este artigo, analisamos as reflexões individuais elaboradas por 31 alunos, correspondendo a 75,6\% do total de alunos(as) que concluíram a disciplina nas suas duas edições. A análise feita dividiu as 31 reflexões individuais em 322 trechos específicos, que foram agrupados de acordo com os temas relativos a cada um dos trechos. $\mathrm{Na}$ análise inicial foram 13 temas escolhidos a partir da leitura dos trechos, conforme mostra a Tabela 1.

Tabela 1: Número de trechos em que cada tema é evocado

\begin{tabular}{|l|c|}
\hline Tema & Trechos \\
\hline Metodologia da disciplina & 49 \\
\hline Outra perspectiva sobre a gestão pública & 48 \\
\hline Problemas dos trabalhadores noturnos & 47 \\
\hline $\begin{array}{l}\text { Intenção de incorporar a vivência na atuação futura como administrador(a) } \\
\text { público }\end{array}$ & 37 \\
\hline Outra perspectiva sobre a cidade & 30 \\
\hline Relação anterior com a "noite" & 30 \\
\hline Reconhecimento dos próprios "privilégios" & 22 \\
\hline Aumento da empatia em relação às dificuldades de outras pessoas & 21 \\
\hline Conhecimentos anteriores sobre gestão pública & 15 \\
\hline Percepções sobre relações desiguais de gênero & 13 \\
\hline Gestão pública intersetorial & 7 \\
\hline Diferenças entre gestões na prefeitura & 3 \\
\hline Total & 322 \\
\hline
\end{tabular}




\section{A noite e a madrugada como períodos de aprendizagem: descrição do caso}

O programa da disciplina é direto ao estabelecer o perfil esperados dos(as) alunos(as): "Por tratar-se de uma Imersão em horário bastante diferente do habitual, espera-se o seguinte perfil: interesse em conversar e interagir com pessoas desconhecidas inicialmente; capacidade de lidar com mudanças prováveis na agenda de campo; disposição para realizar grandes caminhadas; e interesse pela gestão de cidades. Também é obrigatório que tenha disponibilidade total nesta semana, já que o trabalho noturno requererá descansos longos durante os períodos da manhã e tarde."

A disciplina tem carga horária total de 50 horas e ocorre durante uma semana. As aulas começam às $19 \mathrm{~h}$ e terminam às $6 \mathrm{~h}$ do dia seguinte, com atividades durante toda a madrugada. Esse formato só foi possível porque ela ocorre na chamada Semana de Imersão, criada no segundo semestre de 2016 nos cursos de graduação da FGV-EAESP. Essa Semana surge como uma demanda dos(as) alunos(as) do curso de Administração de Empresas para ter experiências de vivência de gestão, tais como seus(suas) colegas de Administração Pública tinham no terceiro, quinto e sétimo semestres, quando realizavam a Imersão Federal, Imersão Local e Conexão Sul-Sul respectivamente. De acordo com Burgos e Teixeira (2019), as chamadas Imersões e Conexões são um dos eixos estruturantes do Curso de AP, buscando ampliar a ideia de Ensino Experiencial. Dessa forma, a vivência dos alunos e alunas em organizações e estruturas administrativas que formulam e/ou elaboram as políticas e ações permite entender o funcionamento do processo de implementação e conhecer instituições e organizações que monitoram, avaliam e fiscalizam os resultados das políticas, buscando uma formação mais completa dos(as) futuros(as) administradores(as) públicos.

A Semana de Imersão está inserida no calendário escolar dos cursos de graduação de Administração de Empresas e Administração Pública e ocorre geralmente no meio do semestre letivo. O objetivo é que professores(as) proponham disciplinas eletivas cuja característica principal é colocar a turma em contato diário com organizações públicas ou privadas. As disciplinas da Semana de Imersão não concorrem com o cotidiano de aulas, exercícios e leituras das demais disciplinas do semestre, uma vez que estas últimas estão interrompidas durante essa semana. Assim, os(as) estudantes podem se dedicar integralmente a uma das Imersões que ele(a) escolheu.

Em todas as edições da Semana de Imersão, as disciplinas ocorrem nos períodos matutino ou vespertino². No entanto, para o objetivo dessa disciplina estes períodos foram transformados em momentos de descanso e reflexão, enquanto a noite e a madrugada se transformaram em períodos de aprendizagem, invertendo a ordem comum do ensino superior em todo o mundo. Embora as atividades noturnas sejam múltiplas, a disciplina está estruturada em quatro eixos, sendo que cada um deles ocupa uma noite e madrugada: abastecimento alimentar noturno (segunda-feira), transporte público noturno (terça-feira), assistência social (quarta-feira) e lazer e entretenimento (quinta-feira). Por se tratar de uma disciplina com organização logística complexa, a turma tem apenas 25 alunos(as). O material a ser levado para o campo inclui apenas um diário de campo para realizar as anotações das conversas - inspiradas na ideia de "pesquisador conversador no cotidiano" de Spink (2008) - e reflexões.

Durante as onze horas diárias de segunda a quinta, as atividades seguem uma divisão de quatro blocos. As aulas começam às $19 \mathrm{~h}$ com uma breve introdução do professor sobre o tema a ser abordado naquela noite. Depois, ocorre uma palestra com agentes públicos de alto escalão (muitas vezes, os secretários municipais) relacionados ao tema. Esse primeiro bloco ocorre na sede da FGV-EAESP e dura até aproximadamente 21h. Depois, o segundo bloco inclui a visita aos equipamentos e órgãos públicos. Neste momento, os(as) alunos(as) já começam a vivenciar a experiência noturna propriamente dita, ao assistir palestra e conversar com os profissionais da administração pública e outros atores que trabalham na madrugada. Nas conversas

\footnotetext{
${ }^{2}$ É importante lembrar que diferentemente de alguns cursos do campo de públicas, na FGV-EAESP, o curso de AP não possui turmas noturnas.
} 
com os(as) trabalhadores(as) noturnos são formadas duplas ou trios de alunos(as) para facilitar o diálogo com essas pessoas, evitando intimidá-las com um grupo grande. O terceiro bloco ocorre no meio da madrugada e tem como objetivo refletir sobre os aprendizados até aquele momento. Esse bloco ocorre normalmente em algum ponto de alimentação (lanchonete ou barraca de pastel) por dois motivos: normalmente, os(as) alunos(as) estão com fome e precisam dessa parada para recuperar as energias, depois de quase sete horas de vivências; trata-se de uma nova oportunidade de interação com profissionais que atuam em estabelecimentos que funcionam durante as 24 horas do dia. No quarto e último bloco, a turma volta a interagir com os(as) trabalhadores da madrugada que estão encerrando suas atividades ou a vivenciar a realidade daqueles que já estão iniciando a sua jornada diária de trabalho. O Quadro 1 traz um resumo das atividades nas duas edições da disciplina, que são acompanhadas durante todo o tempo pelo professor:

Quadro 1: Atividades realizadas pela turma nas duas edições da disciplina

\begin{tabular}{|c|c|c|c|}
\hline $\begin{array}{c}\text { Dia da } \\
\text { Semana }\end{array}$ & Tema & $1^{\circ} \mathrm{sem} / 2018$ & $2^{\circ} \mathrm{sem} / 2018$ \\
\hline $2^{\underline{a}}$ feira & $\begin{array}{l}\text { Abastecimen } \\
\text { to Alimentar }\end{array}$ & $\begin{array}{l}\text { - Palestra sobre o Abastecimento } \\
\text { Alimentar Noturno em São } \\
\text { Paulo, por técnicos do } \\
\text { CEAGESP } \\
\text { - Visita ao Mercado de Flores e } \\
\text { ao Mercado de Pescados do } \\
\text { CEAGESP (conversa com } \\
\text { produtores e consumidores) } \\
\text { - Acompanhamento da } \\
\text { montagem da feira livre da Bela } \\
\text { Vista (conversa com feirantes) }\end{array}$ & $\begin{array}{l}\text { - Palestra sobre o Abastecimento } \\
\text { Alimentar Noturno em São } \\
\text { Paulo, por técnicos do } \\
\text { CEAGESP } \\
\text { - Visita ao Mercado de Flores e } \\
\text { ao Mercado de Pescados do } \\
\text { CEAGESP (conversa com } \\
\text { produtores e consumidores) } \\
\text { - Acompanhamento da } \\
\text { montagem da feira livre da Bela } \\
\text { Vista (conversa com feirantes) }\end{array}$ \\
\hline $3^{\mathrm{a}}$ feira & $\begin{array}{l}\text { Mobilidade } \\
\text { Urbana }\end{array}$ & $\begin{array}{l}\text { - Palestra com Secretário } \\
\text { Municipal de Mobilidade e } \\
\text { Transportes de São Paulo } \\
\text { - Visita à Central de } \\
\text { Monitoramento da Companhia } \\
\text { de Engenharia de Tráfego } \\
\text { (CET-SP) } \\
\text { - Visita à Central de Operações } \\
\text { da SPTrans } \\
\text { - Deslocamento (via ônibus } \\
\text { noturno) até a estação } \\
\text { Corinthians-ltaquera } \\
\text { - Entrevistas/conversas com } \\
\text { usuários de metrô }\end{array}$ & $\begin{array}{l}\text { - Palestra com Secretário } \\
\text { Municipal de Mobilidade e } \\
\text { Transportes de São Paulo } \\
\text { - Visita à Central de } \\
\text { Monitoramento da Companhia } \\
\text { de Engenharia de Tráfego } \\
\text { (CET-SP) } \\
\text { - Visita à Central de Operações } \\
\text { da SPTrans } \\
\text { - Deslocamento (via ônibus } \\
\text { noturno) até a estação } \\
\text { Corinthians-Itaquera } \\
\text { - Entrevistas/conversas com } \\
\text { usuários de metrô }\end{array}$ \\
\hline
\end{tabular}




\begin{tabular}{|c|c|c|c|}
\hline $4^{a}$ feira & $\begin{array}{l}\text { Assistência } \\
\text { Social }\end{array}$ & $\begin{array}{l}\text { Palestra com Secretário } \\
\text { Municipal de Assistência Social } \\
\text { de São Paulo } \\
\text { - Visita à Casa de Oração do } \\
\text { Povo da Rua (Pastoral da Rua) } \\
\text { - Caminhada pelo centro de São } \\
\text { Paulo (Mercado Municipal de } \\
\text { Pateo do Colégio) } \\
\text { - Visita ao Centro Temporário de } \\
\text { Acolhimento Anhangabaú } \\
\text { - Visita à unidade do Bom Prato }\end{array}$ & $\begin{array}{l}\text { - Palestra com Secretário } \\
\text { Municipal de Assistência Social } \\
\text { de São Paulo } \\
\text { - Visita ao Centro de Referência } \\
\text { da Assistência Social Sé } \\
\text { - Acompanhamento junto à } \\
\text { equipe da Coordenadoria de } \\
\text { Proteção Social Especial das } \\
\text { abordagens nas ruas e pontos } \\
\text { de concentração } \\
\text { - Visita ao Centro Temporário de } \\
\text { Acolhimento do Bom Retiro }\end{array}$ \\
\hline $5^{\mathrm{a}}$ feira & $\begin{array}{l}\text { Lazer e } \\
\text { Entretenime } \\
\text { nto Noturno }\end{array}$ & $\begin{array}{l}\text { - Visita aos bares e restaurantes } \\
\text { da Vila Madalena (conversa } \\
\text { com clientes } \\
\text { trabalhadores/as) } \\
\text { - Visita ao 14을 Distrito Policial de } \\
\text { Pinheiros } \\
\text { - Caminhada pela Rua Augusta } \\
\text { (conversa com clientes e } \\
\text { trabalhadores/as) } \\
\text { - Visita ao Batalhão da Polícia } \\
\text { Militar da Praça Roosevelt } \\
\text { - Encerramento das atividades na } \\
\text { Lanchonete Estadão }\end{array}$ & $\begin{array}{l}\text { - Palestra com Juliana Ribeiro } \\
\text { (Prefeita Regional de Pinheiros) } \\
\text { - Visita aos bares e restaurantes } \\
\text { do Largo da Batata (conversa } \\
\text { com clientes } \\
\text { trabalhadores/as) } \\
\text { - Caminhada pela Rua Augusta } \\
\text { (conversa com clientes e } \\
\text { trabalhadores/as) } \\
\text { - Visita ao Batalhão da Polícia } \\
\text { Militar da Praça Roosevelt } \\
\text { - Encerramento das atividades na } \\
\text { Lanchonete Estadão }\end{array}$ \\
\hline
\end{tabular}

Fonte: Elaboração própria.

Antes de ir para campo e mesmo considerando a agenda descrita anteriormente, o professor faz questão de ressaltar que é fundamental "reconhecer que não somos a prioridade" das organizações. Sem dúvida, trata-se de uma recomendação importante, dado que acadêmicos geralmente estão acostumados a serem recebidos com bastante atenção e deferimento. Mas, conforme explicado aos alunos e alunas, durante a noite, a prioridade dos vendedores do CEAGESP é vender as flores e pescados, ao invés de darem entrevistas ou estabelecerem conversas. Isso serve para os técnicos da CET-SP ou da SPTrans que estão monitorando o trânsito de São Paulo, e para os garçons e seguranças dos bares e restaurantes da Vila Madalena, Largo da Batata ou Rua Augusta. Mas, principalmente, é importante para a madrugada de quarta para quinta-feira, quando a prioridade absoluta dos agentes governamentais deve ser a população em situação de rua, dado contexto de extrema vulnerabilidade.

É importante ressaltar que o deslocamento entre as atividades ocorreu de diferentes formas. Algumas delas foram realizadas a pé para que os(as) alunos(as) pudessem sentir sensações semelhantes às que os(as) trabalhadores(as) noturnos sentem como insegurança, sujeira e problemas nas calçadas e na iluminação. Em casos de deslocamentos mais longos, optava-se pelo uso do ônibus noturno ${ }^{3}$ - uma das políticas públicas analisadas pela turma - para verificar a efetividade desse modal de transporte e conversar com os usuários. Em regiões onde não havia corredores de ônibus, o meio de transporte usado era táxi ou Uber, e a turma era também estimulada a conversar com esses profissionais que atuam na madrugada para saber

\footnotetext{
${ }^{3}$ A rede de ônibus da madrugada da capital foi criada pela gestão do prefeito Fernando Haddad e começou a funcionar no final de fevereiro de 2015, com 151 linhas que atendem toda a cidade da meia-noite às $4 \mathrm{~h}$.
} 
os desafios que enfrentam. No início das atividades e no final da madrugada, o metrô ${ }^{4}$ também era usado e novamente, os(as) alunos(as) eram novamente estimulados a conversar com os usuários. Em apenas uma ocasião (nas primeiras madrugadas das duas edições), houve uso do trem metropolitano para o deslocamento do CEAGESP até o metrô.

Em cada uma das edições, na madrugada de quarta pra quinta-feira, os(as) alunos(as) se encontraram com outros professores da EAESP, por aproximadamente uma hora. Na primeira turma, o encontro foi com um professor especialista em segurança pública que acompanhou a visita à Delegacia da Polícia Civil e depois fez um bate-papo sobre segurança pública e os desafios cotidianos para os policiais. Na segunda turma, encontraram com uma professora de sociologia no Largo da Batata, perto de onde ela mora, e puderam debater as mudanças recentes da região e os problemas causados pela gentrificação da área, além de ouvir histórias sobre alguns bares e restaurantes que saíram ou chegaram ao Largo.

Na sexta-feira, último dia da disciplina, a aula ocorre de $16 \mathrm{~h}$ até $23 \mathrm{~h}$. No primeiro bloco, a turma se reúne para elaborar o trabalho final, cujo tema é "Por um gabinete noturno em SP: desafios e possibilidades". Trata-se de um trabalho coletivo, em que é elaborado um único documento por toda a turma. propondo melhorias nos quatro temas estudados durante a semana: abastecimento alimentar, mobilidade urbana, assistência social e lazer e entretenimento noturno. Além disso, a turma deve responder à pergunta "A cidade de São Paulo deveria ter um prefeito noturno" e explicar sua decisão. Nesse momento, grande parte das reflexões das madrugadas anteriores são compartilhadas, assim como as anotações nos diários de campo individuais. No segundo bloco, no início da noite, os(as) alunos(as) apresentam a proposta para o professor e há um debate detalhado sobre cada uma das propostas, analisando a sua viabilidade e explorando melhor determinados temas. No terceiro bloco, há uma roda de conversa entre toda a turma para debater a experiência e sugerir mudanças para as próximas turmas.

\section{4. "A educação pela noite" " a experiência sob a ótica dos(as) alunos(as)}

Embora o perfil dos(as) alunos(as) do curso de Graduação em Administração Pública da FGV-EAESP esteja mudando aos poucos em função do aumento de bolsas não-restituíveis, ainda assim, pode-se considerar que a grande maioria daqueles que participaram da disciplina é de classe média-alta ou classe alta, tendo todos entre 18 e 25 anos de idade. Considerando que o objetivo desta seção do ENEPCP é debater o ensino e a extensão no campo de públicas, a seguir destacaremos o olhar desses(as) alunos(as) - considerando o seu perfil socioeconômico e trajetória familiar - em relação a quatro aspectos. O primeiro deles é a "relação anterior com a noite", ou seja, como a turma entendia os períodos da noite e da madrugada antes da disciplina. O segundo é a metodologia da disciplina, que conforme descrito anteriormente foi inovadora dentro da FGV-EAESP. O terceiro aspecto está relacionado com um dos resultados esperados da disciplina que era aumentar a empatia dos(as) alunos(as) em relação às dificuldades de outras pessoas. E o quarto aspecto também está relacionado com resultados, mas mais focado naqueles relativos ao exercício profissional futuro dentro do campo de públicas.

\section{5. $O$ antes: Relação anterior com a "noite"}

As diferentes visões sobre o que era a "noite" ficaram evidentes logo no primeiro dia de aula, quando cada aluno(a) explicou o motivo de ter escolhido fazer essa disciplina. $E$ a diversidade de opiniões é ainda mais presente nos trechos analisados. Em geral, havia um desconhecimento generalizado sobre o que ocorre nesse período do dia: "O interesse inicial pela disciplina se deu em grande parte pelo desconhecido ou

\footnotetext{
${ }^{4} \mathrm{O}$ horário de funcionamento do metrô de São Paulo varia de acordo com cada estação, mas na maioria das estações o horário de embarque é até 0 h00 e a partir de $4 \mathrm{~h} 40$.

${ }^{5} \mathrm{O}$ título faz referência à obra "A educação pela noite", de Antonio Candido.
} 
misterioso da noite. De modo geral, quem ouve falar do tema tem a reação inicial de: 'eu nunca tinha parado para pensar nisso', no sentido de ser um recorte inesperado". O contraponto sobre o conhecimento das atividades em relação ao período diurno também apareceu: "Em geral, o conhecimento a respeito dos períodos diurnos e vespertinos são mais vastos, uma vez que grande parcela da população das cidades trabalha, estuda e, no geral, está acordada nesses períodos. Já no funcionamento noturno, mesmo sendo essencial, detém compreensão reduzida, pelo fato da vivência populacional nesses períodos serem menores".

Dentre aqueles(as) que optaram por falar sobre suas rotinas anteriores, obviamente, a questão da noite como momento de lazer - remetendo novamente ao título do artigo - apareceu bastante: "Eu não sabia ao certo como seria andar pela cidade de São Paulo durante a madrugada, tendo em vista que, minha experiência noturna era limitada em: festas de faculdades, alguns bares e casas de amigos". Outro trecho comprova essa visão: "Minha experiência noturna na cidade de São Paulo, e em qualquer outra cidade que já fui, se resume a lazer e entretenimento. Seja sair para jantar, ir ao cinema, ou beber, ir a um bar, uma festa, uma balada. Dessa forma, admito raramente ter parado para pensar ou problematizar a vida noturna". Há ainda mais um: "Quando eu pensava gestão noturna antes de fazer a eletiva na semana de imersão tinha apenas a ideia mais fechada de gestão do entretenimento e lazer, o que eu utilizava". Até mesmo o reconhecimento de que o momento de lazer para alguns pode significar problemas para outros apareceu: "Ainda na SPtrans, foi irônico descobrir que os bailes funk das periferias são um grande transtorno para os funcionários do órgão uma vez que compareço aos mesmos e tenho consciência de que para muitos jovens essa é a única alternativa de lazer".

A "invisibilidade da noite" anterior à disciplina também esteve presente nas reflexões: "Antes da matéria, praticamente nunca tinha pensado sobre como a cidade de São Paulo realmente não dorme, pelo menos não para a prefeitura. Desde o recapeamento de ruas até o abastecimento de peixes para toda a grande São Paulo e a fiscalização de bares nas ruas de uma quinta-feira, a prefeitura deve assumir seu papel nessa rotina, organizando-a. Por isso, percebo que agora comecei a reparar nesses detalhes que, mesmo após 6 semestres de AP, eu ainda não tinha percebido como parte do papel do Estado". Outro trecho reafirma isso: "Na verdade, eu nem conhecia o CEAGESP, e foi muito interessante ver de onde vem boa parte da comida que como ou das coisas que compro". Até mesmo questões que fazem parte do cotidiano dos(as) alunos(as) e da comunidade do entorno da faculdade, como a feira livre de terça-feira que funciona a três quadras da sede da FGV-EAESP eram ignoradas: "Foi na visita à feira da Bela Vista que, ao conversar com um casal de comerciantes, percebemos que estes também acordam em um horário bem cedo para comprar sua mercadoria no CEAGESP e revendê-los na feira, ou seja, há toda uma infraestrutura, 'invisível' aos olhos dos cidadãos, para que quando formos a feira comprar nossos produtos, estes estejam por lá".

\section{0 durante: Metodologia da disciplina}

Um dos temas mais presentes foi a metodologia utilizada na disciplina. Um trecho explica a postura que a turma deveria ter durante as noites: "A jornada começou com a leitura do texto 'O pesquisador conversador no cotidiano', que treinou o nosso olhar para o que faríamos: prestaríamos atenção em cada "micro lugar", como diz Peter Spink (...) O pesquisador no cotidiano se caracteriza por conversas espontâneas como forma de abordagem, e eu achei essa visão muito interessante. Senti que usamos muito esse conceito durante a semana, "horizontalizando" a entrevista, tornando-a uma conversa: tínhamos tanto para aprender com uma conversa com um morador de rua quanto em uma entrevista com o Secretário do governo, e eles tinham o mesmo a aprender conosco. Era uma troca, e eu achei isso incrível." A postura de pesquisador conversador se mostrou útil não apenas para a disciplina, mas pode ter efeitos na vida dos(as) alunos(as), como em: "No geral, a disciplina me mostrou formas de conversar com as pessoas e de como eu sou capaz de entender o que elas precisam, sem entrevistá-las formalmente. Esse aspecto me ajuda inclusive em questão de 
evolução pessoal, pois sinto que agora tenho mais vontade de falar com os outros e entendê-los do que medo da possível reação que eles possam vir a ter caso eu fale com eles."

A questão das Imersões e do contato diário com a realidade também esteve presente: "Não há como enfrentar os dilemas que a questão propõe sem chegar perto do que fizemos: ir a campo, colher diferentes visões do assunto, observar de perto aqueles que mais precisam da política e debater exaustivamente 0 assunto." Outro trecho completa: "Estar no mesmo espaço e conversar com carregadores, famílias, compradores, vendedores, seguranças e feirantes me deu uma noção melhor da forma como as políticas públicas, ou a falta delas, são relevantes no dia-a-dia daqueles trabalhadores."

O contato com os gestores também mereceu destaque: "Acredito que a escolha de palestras com profissionais do alto escalão e a posterior conversa com os chamados street level burocrats foi muito positiva para nos mostrar a diferença entre a formulação e a implementação."

A proposta elaborada de deixar com que os(as) alunos(as) ouvissem gestores públicos - tanto formuladores como implementadores - e depois, a população beneficiada ou negligenciada pela política, sem grandes interferências do professor, buscando um aprendizado mais autônomo também foi destacada: "Acredito que além do fato de simplesmente aprendermos na "prática" como funciona a gestão noturna, a metodologia utilizada pelo professor, isto é, desde o fato de permanecermos acordados durante a madrugada até ouvirmos opiniões completamente opostas e, principalmente pela sensibilização perante as outras pessoas que se sacrificam, de certa forma, para que durante o dia as coisas funcionem como o esperado, fizeram com que eu aprendesse a valorizar as condições que tenho e a exercitar minha empatia em relação as demais pessoas". Ainda sobre o papal do professor: "Vale ressaltar que a metodologia utilizada fez com que a experiência se tornasse ainda mais enriquecedora, já que, ele não se colocou como mediador entre nós e o que iríamos estudar de fato, mas sim, nos ajudou a alcançar nosso objetivo somente nos auxiliando."

As dificuldades da metodologia escolhida e do tema também apareceram. A primeira delas foi o cansaço, expressa no relato dessa aluna que falou ao segundo dia, mas depois retomou as atividades e concluiu o curso: "No segundo dia, eu pensei seriamente em desistir da eletiva. Não consegui dormir nada durante a manhã e meu corpo não estava aguentando essa minha nova rotina. Não consegui ir para a imersão. Lembro de pensar se eu conseguiria resistir a uma semana inteira naquela rotina e se no final de tudo, acharia que teria valido a pena. Me senti decepcionada comigo mesma por ter faltado, de forma que, fui para a imersão do terceiro dia". Outros lidaram melhor com o cansaço: "No início de cada noite eu pensava "Ai não, hoje eu definitivamente não vou aguentar'. E aguentava. E não só aguentava, mas aguentava feliz demais. Acho que a gente ia entrando num ritmo mágico e exponencial ao longo da noite, parece que quando chegava $6 \mathrm{~h}$ da manhã o corpo tinha acabado de alcançar o máximo de pique, e poderia continuar por mais horas e horas; mas é bom, também, voltar pra casa e dormir, de novo buscando o equilíbrio."

Outra dificuldade surgiu na madrugada de quinta pra sexta-feira, cujo tema era lazer e entretenimento. À princípio, deveria ter sido o dia mais tranquilo, dado que Vila Madalena, Pinheiros ou Rua Augusta são lugares frequentados cotidianamente pelos alunos(as) da EAESP para momentos de diversão com amigos. Mas isso não ocorreu nas duas turmas: "O último dia de imersão, para mim, seria o mais tranquilo, já que, iriamos frequentas lugares que já frequentamos no nosso cotidiano. Porém, eu estava errada. Senti uma certa dificuldade de abordar as pessoas que estavam no bar socializando com os seus amigos, acredito que seja pelo fato de me colocar no lugar dessas pessoas. Pensei que seria causaria certo incômodo para os entrevistados, e em decorrência disso, a maioria das pessoas que eu entrevistei foram funcionários, como por exemplo: manobristas, seguranças e garçons.". Outro trecho mostra a mesma sensação: "Na quintafeira, o dia era de lazer e entretenimento, por isso fomos até a Vila Madalena e Rua Augusta. Costumo frequentar ambos os lugares, mas não me senti confortável em nenhum deles. Possivelmente, como discutimos posteriormente, isso aconteceu porque é mais difícil entrevistar pessoas que são parecidas com nós mesmas. Quando fui aos outros locais, não conhecia nada sobre aquela realidade, o que me fez ter 
mais curiosidade. No dia de lazer, eu poderia ser a pessoa entrevistada. Além disso, foi o dia em que estava mais cansada e com dor nas pernas. Sinto que não consegui aproveitar da melhor maneira aquela madrugada."

A decisão de apresentar temas e situações complexas foi destacada também: "Ter tido a oportunidade de entender um processo de acolhida de pessoas em situação de rua, desde o início até seu fim, é um grande exemplo de como a imersão se faz necessária, principalmente aliada às discussões promovidas antes e depois das "caminhadas" pela madrugada. É claro que ter essas chances de ver na prática as políticas só são possíveis em momentos específicos do curso, mas fazem uma enorme diferença para a capacidade de abstração dos alunos". Obviamente, a escolha do tema da assistência social visava mostrar aos alunos a complexidade da questão, mas a dificuldade em lidar com a realidade encontrada também ocorreu em outros dias: "O quarto dia foi bastante diferente do esperado. Tendo como macro tema a questão do lazer e entretenimento, achei que seria o dia de maior tranquilidade e descontração. Porém alguns momentos, como a conversa com o morador de rua Richard e encontros com estranhos na praça Roosevelt, foram bastante impactantes, de formas distintas. A fala com Richard foi bastante chocante, pois expos uma situação de total isolamento do resto da sociedade, sendo uma pessoa esquecida pelo governo e invisível para a grande maioria da população. No caso da Roosevelt, os encontros foram mais tranquilos, entretanto mostraram pessoas muito alteradas, algo comum e preocupante, pois a fuga da realidade por meio de drogas é um movimento que pode gerar consequências irreversíveis no ser humano".

Outro aspecto destacado em relação à metodologia escolhida foi apresentar aos alunos as dificuldades de ser pesquisador de campo. O primeiro trecho diz: "Ao chegar no CEAGESP, não esperava ouvir mais de duas horas sobre tipos de peixes, segurança alimentar ou o processo de conservação de alimentos. É um aprendizado de um pesquisador: ouvir aquilo que não está preparado ou muitas vezes aquilo que não tem alto interesse. Mas com um fim: alcançar e responder a sua pergunta de pesquisa, aquilo que realmente lhe interessa. Portanto, foi a primeira aula de empatia que havia tido na eletiva. Saber ouvir os outros é necessário para ser um bom pesquisar e gestor público." Por fim, o gostinho pela pesquisa parece ter agradado bastante alguns alunos: "Ao longo da semana passada, como pesquisadora da noite, me senti novamente uma criança. Entusiasmada e fascinada com os mistérios da noite, anotando páginas e páginas (talvez isso as crianças não façam, rs, mas anotam mentalmente) e me atentando a cada coisinha que acontecia ao nosso redor. E aquelas quase 12 horas de trabalho diário pareciam durar semanas, banhadas pela curiosidade de descobrir mais sobre a noite de São Paulo e a realidade dos que nela habitam."

\section{7. $O$ agora: Aumento da empatia em relação às dificuldades de outras pessoas}

Em relação ao aumento da empatia, os primeiros trechos destacados são mais genéricos em relação à disciplina: "Foram 4 noites em claro (re)descobrindo São Paulo, suas belezas e suas agruras e, de uma maneira muito superior àquela esperada por mim, me deparando com as particularidades de grupos insistentemente colocados à margem da sociedade, quando não cuidados e sustentados por uma força familiar. São eles: idosos, crianças, mulheres, etc.". Em outro trecho: "A disciplina me deixou mais humana e com maior empatia por essas pessoas que vivem em função da noite, horário que muitos disseram que o corpo não foi feito para funcionar, deixando o meu olhar não apenas voltado para a parte administrativa da gestão noturna, mas principalmente para personalizar e me colocar no lugar destas pessoas que estão nas ruas e que são em grande parte responsáveis para o funcionamento da cidade durante o dia". Até mesmo a possibilidade de uma nova postura do(a) aluno(a), a partir dessa aproximação, também surgiu: "A matéria me trouxe mais humanidade em lidar com os outros, mas não porque eu os entendi, e sim porque agora eu me permito aproximar deles".

A necessidade do aumento de empatia para além da disciplina, mas principalmente em função da escolha de um curso do campo de pública apareceu em alguns trechos: "Estar na rua observando os diferentes 
contextos e a especificidade de cada ser humano que está ali é, sem sombra de dúvidas, primordial. Mesmo porque, sem este olhar (o qual, caracterizo como empatia) dificilmente será possível que um gestor realize políticas públicas que satisfaçam a esta e outros níveis populacionais". Ou aqui: "Chega a ser curioso ter de explicitar essa característica num curso de gestão pública de qualquer especificidade, dado que um pressuposto da paixão pelo interesse público concentra-se, para mim, na empatia e na vontade de dedicarse ao outro. Entretanto, não apenas essa não é a realidade da escolha para muitos que a fazem, como também é bastante fácil perder-se nos frios detalhes processuais e técnicos. Por isso, considerei a experiência algo revigorante, lembrete necessário a nós, alunos e aspirantes a gestores públicos".

Novamente, a invisibilidade anterior dos problemas esteve presente: "A experiência no Ceagesp e no dia seguinte, com o transporte público noturno, me incomodaram bastante porque as questões trazidas pelas pessoas não eram necessariamente questões imperceptíveis no meu dia a dia. Em idas anteriores, era absolutamente possível perceber que o trabalho feito pela carregadores é precário e isso não aconteceu porque essas pessoas são socialmente invisibilizadas, muito em decorrência do próprio trabalho, e meu olhar não estava atento ou preocupado com nada além de comprar as flores que eu precisava". Ou em outro trecho: "O incômodo, no caso do transporte, está relacionado ao fato de que eu nunca considerei seriamente o transporte noturno como um serviço importante, o que se relaciona muito com o fato de não ser uma demanda pessoal. Esses incômodos não significam que eu acredite que eu tenha que pensar em todos os problemas da sociedade para solucioná-los, mas, em contrapartida, me faz questionar quais são os problemas, as pessoas e as demandas que a gestão pública não considera porque as pessoas que estão no governo não necessitam de determinada ação do Estado". Ainda na noite da assistência social: "O principal efeito foi sobre a as lentes enviesadas que eu usava para a questão dos moradores de rua: agora que eu conheço mais quem eles são, o que fazem (ou até o que não fazem) e, mais importante, quais as diferenças entre eles, eu tenho um olhar muito mais humano e preparado para lidar com essa parte da assistência social."

Inicialmente, a noite da assistência social parecia mesmo a com maior potencial para gerar o aumento da empatia: "Pessoalmente, essa foi a noite que trouxe menos respostas e mais dúvidas e angústias. Subir em uma van da Assistência Social para recolher as pessoas interessadas para irem para abrigos, mostra o tamanho da complexidade da questão. Dentro daquelas vans viajam diariamente pessoas completamente diferentes, com necessidades, agendas e anseios próprios, senhores de suas próprias histórias e que ali, vivem um translado para um banho, refeição quente e um quarto para passar a noite, desde que se submetam a uma série de regras. Mesmo assim, isso tudo parece ser ineficiente para trazer algum tipo de amparo, e minha visão sobre o assunto é um tumulto entre emoções e racionalidade". A proximidade com a população em situação de rua também apareceu: "Eu sabia que havia pessoas dormindo nas ruas do centro de São Paulo, mas nunca havia andado por lá, parado e olhado. Essa percepção mais sensível sobre alguém que dorme nas ruas, trabalha a madrugada inteira ou precisa pegar cinco ônibus para chegar ao trabalho me fez ter a certeza que Administração Pública foi minha melhor opção. Mais que isso, fugi da bolha gvniana na qual a maioria dos alunos têm roupas, acessórios, cabelos e vidas similares". A análise dessa população, mas dentro dos equipamentos também teve destaque: "Foi um choque saber que no CTA tem gente formada em direito, gastronomia, que fala até 8 línguas. Isso só reforça o que Ana disse: morador de rua pode ser qualquer um. Lá, eles aceitam todos. (...) Ao conversar com os frequentadores, percebi que sua principal demanda é trabalho. Ademais, tive a impressão que o CTA parece um pouco uma prisão, mas o clima lá dentro pareceu bom comparado ao que eu achava."

Entretanto algumas experiências - como a ida à Feira de Pescados do CEAGESP, com os seus gritos, cores e cheiros - parecem também ter sido especialmente impactantes para alguns: "Além disso, chegar em casa, após a visita ao pescado e à feira da Bela Vista, foi instantâneo a sensação de exaustão e também o cheiro forte de peixe que havia ficado no meu corpo. A insalubridade daqueles trabalhadores foi em um momento sentida por mim. Não era só mais um espectador daquilo, mas sim, um ator por um dia daquela história. 
Acredito que esse entendimento do que é voltar para causa exausto, após uma madrugada caótica e ainda com odor de peixe pelo corpo é uma sensação que foi vivida para ser criada e mimetizando de certa forma a vida de alguém. Mas é claro que nunca sentirei por completo aquilo que os trabalhadores, por exemplo do pescado, sentem. Não vivo a mesma realidade, não tenho a mesma profissão e fiz aquilo uma única noite. Aquele não é o meu lugar, mas poder compreende-lo de fora é importante para construir políticas que tentem reparar danos, injustiças ou desigualdades, a fim de tentar tornar aquele trabalho mais aprazível."

\section{0 depois: Intenção de incorporar a vivência na atuação futura como administrador(a) público}

Ainda como resultado, mas este esperando-se que aconteça no longo prazo, vários trechos apontaram para a futura atuação como administrador(a) público dos então alunos(as). Alguns são mais genéricos em relação ao tema como "um sentimento muito bom de se ter ao se encontrar na reta final da graduação foi o de não ter dúvidas de que escolhi o curso certo, tal como me senti durante a eletiva" ou "gestão noturna veio para ficar, não pretendo esquecê-la" e também "a partir dela, penso a madrugada como algo a ser explorada, como um pontinho de inquietação interno que levarei comigo para as próximas fases da minha vida". Outras, um pouco mais relacionado com as perspectivas profissionais: "Ainda existem muitos campos ligados à noite de São Paulo que não puderam ser vistos nesta última semana, mas a experiência prática da ida aos locais e conversas com muitos dos que cruzaram nossos caminhos nos últimos dias fez da gestão noturna um tema muito interessante e que ganhou destaque dentro do meu panorama da administração pública municipal".

Mas há trechos bastante enfáticos sobre o futuro na gestão pública: "A sensação de familiaridade entra em conflito com as muitas novas informações, contextos e históricos recebidas que, de relance, podem parecer escusos ao nosso cotidiano. É importante perceber a existência do diferente tão próximo de nós. E é essencial, especialmente para nós, enquanto gestores públicos, carregar-se de compromisso em agir em favor dele, empaticamente". A soma de mais essa competência em relação a tantas outras que o curso dá também apareceu "Por todas essas razões, a experiência adquirida na última semana faz-se essencial na vida de um administrador público (para não falar na de um ser humano engajado). Observar o estranho, de maneira a propor-se a adentrar afetivamente seu universo, ao mesmo tempo que atentar-se às esferas política, técnica, conjuntural e administrativa dos problemas observados soma-se em ganhos desmedidos a nossa experiência". A ideia de que uma semente foi plantada veio neste trecho: "A semana de horários invertidos trouxe uma série de experiências e aprendizados acerca da realidade paulista quase não vista. Parte do ensinamento deixado está relacionado com as dúvidas e inquietações que foram deixadas. 0 sentimento de desconforto com uma série de coisas é presente, o que provavelmente servirá de semente para ao menos a busca por transformação por parte de uma série de alunos de administração pública".

"Em alguns anos, parte considerável desse corpo será composta de administradores públicos, tomadores de decisões com uma sensibilidade mais aguçada acerca de pontos muito sensíveis. Vivenciar a realidade de outras pessoas (mesmo que por tão pouco tempo) pode se mostrar algo transformador na vida daqueles que a experimentaram" foi mais um trecho sobre o futuro. A necessária transformação do Estado foi mencionada neste trecho sobre o período noturno: "A questão que se coloca é que a nós, como futuros integrantes do governo, não consta optar por ignorar tudo o que acontece durante esse período. Pelo contrário: a existência do Estado só faz sentido na medida em que este busque atender às necessidades fundamentais das pessoas, buscando fazê-lo de forma sustentável, em todos os sentidos da palavra. E atender a todas as pessoas significa atentar-se para não excluir nenhuma minoria - seja de gênero e orientação sexual, seja econômica, seja racial, seja noturna".

Para finalizar, um trecho que relembrou um momento da madrugada de quarta para quinta-feira, quando depois de uma longa caminhada pelo centro de São Paulo, observando atentamente a realidade do período noturno, o grupo parou para tirar uma foto de lembrança da experiência e do momento: "A 'Fonte dos 
Desejos' localizada em frente ao suntuoso Theatro Municipal foi o local em que dezesseis futuros administradores públicos e duas futuras administradoras privadas fizeram uma foto em uma madrugada de São Paulo. Esse momento simbólico representou nosso objetivo de perceber os problemas e demandas da população noturna, portanto, esse olhar sensível que se fez presente nesse grupo é a mensagem subliminar de esperança e beleza em relação ao caos brasileiro. Foi uma semana em que desejos foram feitos, pelas mais diversas pessoas, direto na fonte da futura administração do país".

\section{Desafios do ensino na (e sobre a) madrugada: por um fechamento que chame uma abertura}

Pensar na gestão noturna de uma cidade é bastante complexo. De um lado, ela requer um olhar mais atento e sensível a questões que são invisíveis para a grande maioria da população. Quer dizer, estas questões só são invisíveis porque funcionam - e relativamente bem - no período da noite. Afinal, eventuais falhas que ocorram nas atividades noturnas - como o atraso em uma obra de recapeamento de avenida ou a não entrega de alimentos a um restaurante popular, por exemplo - podem afetar o cotidiano de milhares de habitantes na manhã seguinte. Assim, quando tudo ocorre normalmente, esses serviços noturnos tendem a passar de maneira despercebida pela população, cuja vida foi organizada enquanto dormia. De outro lado, requer uma visão mais moderna da administração pública, pensando nas oportunidades sociais e econômicas que o período noturno oferece para as cidades. Os exemplos internacionais parecem trazer resultados bastante interessantes no sentido econômico. Mas em países extremamente desiguais como 0 Brasil, é preciso pensar nas pessoas em situação de rua e nas condições de mobilidade e de trabalho dos profissionais que atuam na madrugada ou estão iniciando suas jornadas laborais durante esse período.

Realizar uma disciplina sobre a gestão noturna de uma cidade é também muito complexo. Em primeiro lugar, é preciso vencer a resistência das estruturas administrativas da instituição educacional, cujo funcionamento normalmente é de $6 \mathrm{~h}$ até $23 \mathrm{~h}$. Depois, é preciso convencer os(as) colegas e coordenadores sobre a seriedade e a viabilidade da disciplina, ainda que obviamente possa haver riscos, principalmente nos deslocamentos durante a madrugada. Em segundo lugar, é fundamental possuir ou construir uma rede de contatos com as instituições governamentais para que elas possam receber a turma em horário pouco habitual, assim como estejam dispostos a ministrar palestras no período noturno. Depois, é preciso contar com um grupo de alunos(as) colaborativos, empáticos e motivados com a experiência, pois isso é fundamental para lidar com o cansaço natural e com o relógio biológico alterado. Nesse sentido, um complicador ocorre quando parte dos(as) alunos(as) não consegue se desvencilhar de outros compromissos no período diurno, como estágios, trabalhos, aulas extra-curriculares, ou assuntos familiares, e portanto, não conseguem dormir durante o dia. Por fim, é preciso contar também com um pouco de sorte para não chover - ou ao menos, não chover muito -, para que não haja mudanças na agenda estabelecida e para que não haja problema de segurança, o que é sempre arriscado em grandes metrópoles como São Paulo.

As duas edições realizadas até agora foram bastante exitosas, conforme apresentado nos relatos e os aprendizados dos(as) alunos(as) parecem ter sido interessantes. Em termos de conhecimento sobre o fazer pesquisa, trata-se de uma experiência bastante prática de como abordar pessoas diferentes e fazer entrevistas/conversas. Para fins de aumento de empatia, a observação das dificuldades que enfrentam outras pessoas pode ajudar a mudar comportamentos. E por fim, perceber que a noite é muito mais do que o momento de lazer e diversão, mas também é o momento de trabalho muito duro para alguns profissionais e de extrema atenção para a Administração Pública, principalmente de uma cidade complexa como São Paulo.

Os temas de abastecimento alimentar, mobilidade urbana, assistência social, e lazer e entretenimento são muito frutíferos. Mas caso outros(as) professores(as) do campo de públicas queiram experimentar uma disciplina durante a noite e a madrugada, certamente, há muitos outros temas, como limpeza urbana, saúde, serviço funerário, vendedores ambulantes de café da manhã, recapeamento asfáltico etc. Com certeza, o 
aprendizado em todos eles pode ser enorme e com isso, ajudaremos a formar futuros profissionais mais competentes e comprometidos com a melhora da gestão pública brasileira e a redução das nossas múltiplas desigualdades, que não deixam de existir à noite.

\section{Referências}

BODY-GENDROT, Sophie. Nights in the Global City. In: BRIDGE, Gary \& WATSON, Sophie (eds). The new Blackwell companion to the city. West Sussex: Wiley-Blackwell, 2011.

\section{Bowen}

CANDIDO, Antonio. A educação pela noite. São Paulo: Ouro Sobre Azul, 2011, 6ª ed.

HADFIELD, Phil. Bar wars: contesting the night in contemporary British cities. Oxford: Oxford University Press, 2006.

HOLLANDS, Robert \& CHATTERTON, Paul. Producing Nightlife in the New Urban Entertainment Economy: Corporatization, Branding and Market Segmentation. International Journal of Urban and Regional Research, Volume 27.2, June 2003, pp. 361-385.

NOFRE, Jordi. “Vintage Nightlife”: Gentrifying Lisbon downtown. Fennia 191: 2, 2013, pp. 106-121.

SANTOS, Fernando Burgos Pimentel dos; TEIXEIRA, Marco Antonio Carvalho. Inovações e Desafios Metodológicos no Ensino de Administração Pública no Brasil: um Olhar com Base no Curso da FGV-EAESP. Administração: Ensino e Pesquisa, [S.I.], v. 20, n. 1, p. 211-230, jan. 2019.

SPINK, Peter. O pesquisador conversador no cotidiano. Psicologia \& Sociedade, v. 20, 2008, pp. 70-77.

STAKE, R. Case Studies. In: DENZIN, N.; LINCOLN, T. Handbook of Qualitative Research. London: Sage, 2005

TALBOT, Deborah. Regulating the Night Race, Culture and Exclusion in the Making of the Night-time Economy. Hampshire: Ashgate, 2007.

. The juridification of nightlife and alternative culture: two UK case studies. International Journal of Cultural Policy. Vol. 17, No. 1, January 2011, pp. 81-93. 